\title{
Gay fathers' reproductive journeys and parenting experiences: a review of research
}

\author{
Damien W Riggs, ${ }^{1}$ Clemence Due ${ }^{2}$
}

${ }^{1}$ Associate Professor, School of Social and Policy Studies, Flinders University, Adelaide and Visiting Research Fellow, School of Psychology, The University of Adelaide, Adelaide, Australia ${ }^{2}$ Postdoctoral Research Fellow, Southgate Institute for Health, Society and Equity, Flinders University, Adelaide, Australia

\section{Correspondence to}

Dr Damien W Riggs, School of Social and Policy Studies, Flinders University, GPO Box 2100, Adelaide, SA 5001, Australia; damien.riggs@flinders.edu.au

Received 23 August 2013 Revised 21 July 2014 Accepted 26 July 2014

\begin{abstract}
Over the past decade growing numbers of gay men have sought and found ways to become parents, including through surrogacy, giving birth, adoption and fostering. These modes of family formation are situated alongside preexisting modes of family formation available to gay men, specifically in heterosexual relationships and through donating sperm to lesbian recipients. This review article summarises the literature related to each of these modes of family formation. It highlights the discrimination that gay men may face as parents and the positive outcomes both for gay fathers and for the children they parent.
\end{abstract}

\section{INTRODUCTION}

Over the past two decades gay men living in Westernised societies have increasingly sought ways of becoming parents. ${ }^{1}$ As outlined below, prior to the new millennium, most gay men who became fathers did so either in the context of a previous heterosexual relationship, or through the donation of sperm to lesbian recipients with whom they entered into some form of parenting relationship. In the present millennium, as a result of the availability of 'off-shore' surrogacy as a financially viable option for an increasing number of people and the removal of laws and policies that had previously excluded gay men in many countries from fostering or adopting children, a much wider range of opportunities is available to gay men who wish to become parents. This review presents a brief summary of previous empirical research on the experiences of gay men who are parents. It examines the differing pathways that gay men follow towards becoming fathers, exploring the unique experiences associated with each pathway, as well as the similarities across those pathways.

\section{Key messages}

- Gay men become parents through multiple pathways, each of which is valid, and none of which should be privileged over another.

- Given the fact that most gay men cannot carry a child, women's bodies are intimately connected to gay men's experiences of becoming parents.

- Gay men's reproductive desires are valid and must be treated with respect, and their competency to become parents treated as a generally accepted principle.

\section{GAY MEN WHO BECOME PARENTS VIA HETEROSEXUAL RELATIONSHIPS}

A significant number of men who identify as gay will have had children in the context of a previous heterosexual relationship. For some, ongoing contact and close relationship with their children (and in many cases their ex-partners) are the norm. Other men, however, have faced the loss of parental rights to their children upon disclosing their homosexuality. For these men, the decision to leave the marriage and disclose their homosexuality is significant.

Early research in the USA by Bigner and Jacobson compared 33 men who had their children in the context of a heterosexual relationship, but who at the time of the research identified as gay and continued to be involved in parenting their children, with 33 men who identified as heterosexual and who were fathers. ${ }^{2} 3$ The research found that the two groups reported similar levels of involvement and intimacy with their children. In terms of differences between the groups, 
the gay fathers tended to be more strict with their children, more responsive to their needs and more consistent in their parenting style. Barrett and Robinson echo this point about gay fathers' responsivity, suggesting that some gay men who continue to parent after leaving a heterosexual relationship may feel driven to provide a high standard of parenting so as to counter negative evaluations of their homosexuality. ${ }^{4}$

A further notable point of difference between gay and heterosexual fathers found by Bigner and Jacobson was that the gay fathers in their sample suggested that having children enhanced their masculinity (in a context where identifying as gay was often read as denoting femininity), and that being a father facilitated entrance and acceptance in the general, nominally heterosexual community. Higgins' Australian survey study found similarly that gay men who had children while in a heterosexual relationship reported the belief that both being married and having children would bolster their masculinity and facilitate acceptance into the broader community. ${ }^{5} 6$ Of Higgins' sample of 69 men, $65.4 \%$ married because of a desire to have children, the perception being that this was only possible through a relationship with a woman. Given that these data were collected after 2000, it is important to note their similarity to Bigner and Jacobson's ${ }^{2}$ data from over a decade earlier. This would suggest that whilst legislative and attitudinal change may occur, this does not necessarily transfer to the everyday knowledge of gay men, nor to their decisions about becoming parents.

\section{GAY MEN WHO BECOME PARENTS VIA SPERM DONATION}

In the 1980s there existed a perception within lesbian and gay communities that gay men might be the 'safest' sperm donors for lesbian women in private arrangements (i.e. outside of fertility clinics), a perception that presumed allegiances between lesbians and gay men in the face of homophobia. ${ }^{7}$ Such arrangements were necessary as women who identified as lesbian were not eligible to access donor sperm within clinics. Gay men's role as sperm donors to lesbian women has, however, been shown to be somewhat problematic. Largely this is because research on sperm donation has indicated that the most 'ideal' donors, those who are willing to be identified by children conceived of their donation, but who do not necessarily desire an active parenting role in the child's life, are men who have previously had their own children. ${ }^{8}$ Until recently few gay men had their own children, so the discrepancy between gay men being perceived as ideal donors and their adherence to the 'ideal donor' profile has resulted in cases where gay men have sought custody, or parental involvement, with children conceived of their donations. ${ }^{7}$
Despite debate over whether or not gay men who have not had children previously are 'ideal' donors for lesbian recipients, the pairing of lesbian recipients and gay donors continues. Some of these men, by negotiation prior to donation, play an active role as fathers to the child(ren) born of their donations, and do so in collaboration with the children's mothers. Qualitative research with gay sperm donors who play a parental role suggests that the relationship between gay 'donor dads' and lesbian recipients is complex, with some men stating that they believe children conceived of their donations need male role models, and that acting as a donor for lesbian recipients entitles gay men to have a voice in decisions about children conceived of their donations. ${ }^{9-12}$ Other men report positive and supportive relationships with the lesbian recipients of their donations.

Quantitative research by Bos reported on a matched sample of 36 gay men who became fathers through sperm donation to lesbian recipients and 36 heterosexual fathers. No significant differences were found between the samples in terms of emotional involvement and parental concern, nor in terms of any of the measures of children's well-being. ${ }^{13}$ The main difference identified was in terms of perceived competency in child-rearing: gay donor fathers reported feeling more incompetent than heterosexual fathers did. Importantly, however, this finding must be viewed in the light of the fact that none of the children lived solely with their fathers, and only $36.1 \%$ of the gay fathers reported that their children lived with them half of the time, the children of the remainder living primarily with their mothers.

\section{GAY MEN WHO BECOME PARENTS VIA FOSTER CARE}

Foster care as a mode of family formation for gay men is highly dependent on the specific legislature in which such men live for two reasons. The first relates to whether or not the legislature utilises foster care as a long-term mode of care for children who cannot live with their birth parents. In Australia, for example, long-term foster care, as opposed to adoption, is the currently preferred model of such care. In the USA (and largely also now in the UK), adoption is the preferred model, with foster care used primarily as a transition prior to adoption. Secondly, in some locations foster care is open to all applicants, whilst in others only heterosexually-married couples may apply.

Whilst there are a number of studies focusing on lesbian and gay foster carers as a homogenous group, ${ }^{14} 15$ only two papers were identified that focus specifically on gay men as foster carers. One of these argues that the low number of gay foster carers is a result of the devaluing of gay men as parents, ongoing stigma attached to gay men as parents, and 'heteronormativity' within foster care agencies. ${ }^{16}$ The second reports on one gay man's experience with foster care, 
outlining a number of similar experiences of discrimination by foster care organisations and the general public. ${ }^{17}$

\section{GAY MEN WHO BECOME PARENTS VIA ADOPTION}

Similarly to foster care, adoption as a route to parenting for gay men is governed both by whether or not adoption is commonly available, and whether it is available to gay men. For example, in Australia, whilst some states are now legislating to allow lesbians and gay men to adopt, the fact that approximately only 300 children are placed for adoption each year (as opposed to 30000 children per year living in foster care) means that the opportunities for gay men to adopt are relatively few.

Most of the research on gay men and adoption has been undertaken in the USA. The work of Farr et al. has investigated similarities and differences between lesbian, gay and heterosexual adoptive couples. ${ }^{18} \mathrm{In}$ terms of similarities, their quantitative research found no significant difference between each group on measures of child adjustment, parenting behaviours or couple adjustment. In terms of differences, their research found small but significant differences, wherein the children of lesbian or gay parents were described as having fewer behavioural problems than the children of heterosexual parents. Looking at 230 gay adoptive parents in the USA, Tornello et al. found that sensitivity to stigma appeared to be unique to gay men as adoptive parents, in that the men in their study who reported higher levels of sensitivity to gay-related stigma also reported higher levels of parenting stress. ${ }^{19}$

New UK comparative research on adoption indicates similar findings to those identified in USA research. Golombok and colleagues compared measures of parental well-being and child adjustment between heterosexual, lesbian and gay adoptive families. ${ }^{20}$ Their findings suggest that parental well-being was more positive in gay families as compared to heterosexual families, and that adoptive children in heterosexual families displayed higher levels of externalising problems than did children in gay families.

Qualitative research from the USA further highlights some of the specific experiences of gay men who adopt. Downing et al.'s interviews with 32 gay adoptive parents found that men encountered discrimination in the adoptive process, including sometimes having to hide their relationship; only one man being able to be the legal parent; and having negative experiences with particular adoption agencies that would not work with them as gay couples. ${ }^{21}$

\section{GAY MEN WHO BECOME PARENTS VIA SURROGACY ARRANGEMENTS}

Over the past decade increasing numbers of gay men living in Westernised countries have entered into surrogacy arrangements through which they may become parents. Such arrangements may be either altruistic (i.e. not for payment, with the surrogacy often undertaken by someone already known to the intended parents) or commercial (i.e. with payment made to the woman who acts as the surrogate). Another distinction must be made between gestational surrogacy (where the woman who acts as a surrogate is implanted with an embryo created from a donor egg) and arrangements where the woman who acts as a surrogate uses her own ovum, though this practice is less common. A further difference relates to whether or not the surrogacy occurs 'onshore', primarily in the USA and UK, where citizens utilise surrogacy services within their home country, or offshore, where citizens of one country hire a woman to act as a surrogate in another country and then collect the child and bring it home to their own country.

Given the complexities of surrogacy, there are diverse opinions about its ethics. These cannot be covered adequately in this review, but a summary is provided by Riggs and Due. ${ }^{22}$ Also, given the relative recency of large-scale commercial surrogacy, there is relatively little empirical research on outcomes for families formed through such arrangements. A recent study by Kruczkowski ${ }^{23}$ with 52 gay men in the USA examined a number of factors arising from the experiences of coupled gay men who had children through surrogacy arrangements. Participants reported a relatively equal division of household labour, and that the most significant factors predictive of relationship quality were the amount of paid work hours and satisfaction with division of labour. Those who worked longer hours in paid work and those who felt less satisfied with the division of household labour rated their relationship quality lower. Notably, no differences were found between participants in terms of which partner's sperm had been used in the conception of their children.

This last finding is interesting given that both Dempsey's and Murphy's Australian interview research found that genetic relatedness is frequently emphasised amongst gay couples who become parents through a surrogacy arrangement. ${ }^{24} 25$ Both these studies suggest that gay couples often enter into complex negotiations over whose sperm will be used, and that ongoing family identity management is undertaken either to ensure that this information is kept secret, or that it does not affect the equal treatment of both men as fathers. It is perhaps the latter desire that shaped why no differences were found in Kruczkowski's ${ }^{23}$ study in terms of the influence of genetic relatedness upon the quality of the relationships.

\section{GAY MEN WHO BECOME PARENTS VIA GIVING BIRTH}

At first sight it may appear surprising to suggest that some gay men become parents via giving birth. Yet if 
we understand natally-assigned sex and gender identity as two separate, albeit related, features of any individual's sense of self, then it may be more apparent how it is that some gay men may give birth. Specifically, it is possible for transgender gay men (i.e. people who were assigned female at birth but who identify as gay men) who choose to retain their reproductive organs to become pregnant through the use of donor sperm (either from a cisgender male partner or from a donor).

Empirical research in this area has only very recently been undertaken, and just two studies were identified on the topic. The first of these reported on a questionnaire study with 50 transsexual men living in Belgium. Five of the sample reported a homosexual orientation. Eleven of the sample already had children, with 27 desiring to have children in the future. The men who had children scored higher on selfperceived mental health than did those who did not have children. ${ }^{26}$

A qualitative analysis conducted by Riggs both of previous research on transgender men (where mention was made of children) and of recent documentaries featuring transgender men who had children (including some gay transgender men) identified a number of key issues facing this group. ${ }^{27}$ For these men, bearing a child made them feel as though their body - previously marked as female - had some purpose (here specifically with reference to breastfeeding). Many such men reconciled their masculine identity with their pregnancy by referring to the pregnancy as though it was someone else's.

\section{CONCLUSIONS}

As this review has outlined, there are many pathways to parenthood for gay men, each of them bringing differing demands both for gay parents and for the clinicians who work with them. Whilst not evident in all of the research summarised in this review, discrimination is a common experience for gay men in general, and gay fathers specifically. ${ }^{28}$ Such discrimination may come from gay men's own families, from childcare providers, from schools, from medical professionals and from broader society. Ongoing negative stereotypes about gay men and children continue to shape how outsiders view gay parents and how they engage with them. ${ }^{16}$

While the research summarised in this review highlights similarities and differences between gay and heterosexual fathers, the overarching finding is that children raised by gay fathers do as well as children raised by other parents. Clinicians have an important role to play in facilitating the best possible start to family life for all parties involved in gay-father families by ensuring the adequate provision of information, and by ensuring that this is done in an environment free from judgment.
Funding The production of this manuscript was supported by a grant from the Australian Research Council (DP110101893).

Competing interests None.

Provenance and peer review Commissioned; externally peer reviewed.

Editor's note Readers who are interested in this topic will also find much of interest in a BBC Radio 4 Book of the Week last year, entitled Far from the Tree: Parents, Children and the Search for Identity by Andrew Solomon. London, UK: Vintage Books, 2014. ISBN-13: 978-0-099-46099-2. Price: £11.99. Pages: 976 (paperback).

\section{REFERENCES}

1 Patterson C, Tornello S. Gay fathers' pathways to parenthood: international perspectives. J Fam Res 2010;22:103-116.

2 Bigner JJ, Jacobson RB. The value of children to gay and heterosexual fathers. J Homosex 1989;18:167-172.

3 Bigner JJ, Jacobsen RB. Adult responses to child behavior and attitudes toward fathering: gay and nongay fathers. J Homosex 1992;23:99-112.

4 Barret R, Robinson B. Gay Fathers. New York, NY: Free Press, 1990.

5 Higgins DJ. Gay men from heterosexual marriages: attitudes, behaviors, childhood experiences, and reasons for marriage. J Homosex 2002;42:15-34.

6 Higgins DJ. Living with contradictions: experiences of same-sex attracted men within heterosexual marriage. In: Riggs DW, Walker GA (eds), Out in the Antipodes: Australian and New Zealand Perspectives on Gay and Lesbian Issues in Psychology. Perth, Australia: Brightfire, 2004:132-154.

7 Dempsey D. 'Donor, father or parent? Conceiving paternity in the Australian Family Court'. Int J Law Policy Fam 2004;18:76-102.

8 Riggs DW, Russell L. Characteristics of men willing to act as sperm donors in the context of identity-release legislation. Hum Reprod 2011;26:266-272.

9 Van Reyk P. Baby love: gay donor father narratives of intimacy. Gay Lesbian Issues Psychol Rev 2007;3:44-52.

10 Dempsey D. More like a donor or more like a father: gay men's concepts of relatedness to children. Sexualities 2012;15:156-174.

11 Riggs DW. Lesbian mothers, gay sperm donors, and community: ensuring the well-being of children and families. Health Sociol Rev 2008;17:232-240.

12 Scholz B, Riggs DW. Sperm donors' account of lesbian recipients: heterosexualisation as a tool for warranting claims to children's 'best interests'. Psychol Sex 2014;5:247-257.

13 Bos HH. Planned gay father families in kinship arrangements. Aust N Z J Fam Ther 2010;31:356-371.

14 Hicks S. Queer genealogies: tales of conformity and rebellion amongst lesbian and gay foster carers and adopters. Qual Soc Work 2005;4:293-308.

15 Riggs DW. Australian lesbian and gay foster carers negotiating the child protection system: strengths and challenges. Sex Res Social Policy 2001;8:215-226.

16 Hicks S. Maternal men - perverts and deviants? Making sense of gay men as foster carers and adopters. J GLBT Fam Stud 2006;2:93-114.

17 Dennis P. The story of a gay foster parent. Child Welfare 2006;85:123-132.

18 Farr RH, Forssell SL, Patterson CJ. Parenting and child development in adoptive families: does parental sexual orientation matter? Appl Dev Sci 2010;14:164-178. 
19 Tornello S, Farr R, Patterson C. Predictors of parenting stress among gay adoptive fathers in the United States. J Fam Psychol 2011;25:591-600.

20 Downing J, Richardson H, Kinkler L, et al. Making the decision: factors influencing gay men's choice of an adoption path. Adoption Q 2009;12:247-271.

21 Golombok S, Mellish L, Jennings S, et al. Adoptive gay father families: parent-child relationships and children's psychological adjustment. Child Dev 2014;85:456-468.

22 Riggs DW, Due C. Gay men, race privilege and surrogacy in India. Outskirts: Feminisms Along the Edge 2010;22.

23 Kruczkowski S. Gay men becoming fathers via surrogacy: division of labor and relationship quality. Distinguished Master's thesis, University of Virginia, Charlottesville, VA, USA, 2012.
24 Dempsey D. Surrogacy, gay male couples and the significance of biogenetic paternity. New Genet Soc 2013;32:37-53.

25 Murphy DA. The desire for parenthood: gay men choosing to become parents through surrogacy. J Fam Issues 2013;34: 1104-1124.

26 Wierckx K, Can Caenegam E, Pennings G, et al. Reproductive wish in transsexual men. Hum Reprod 2012;27:483-487.

27 Riggs DW. Transgender men's self-representations of bearing children post-transition. In: Green FJ, Friedman M (eds), Chasing Rainbows: Exploring Gender Fluid Parenting Practices. Toronto, Canada: Demeter Press, 2013.

28 Armesto JC. Developmental and contextual factors that influence gay fathers' parental competence: a review of the literature. Psychol Men Masc 2002;3:67-78.

\section{FACULTY OF SEXUAL \& REPRODUCTIVE HEALTHCARE MEMBERSHIP EXAMINATION}

The Membership Examination (MFSRH) consists of:

\section{Part 1 Single Best Answer paper (SBA)}

The London-based examination is held annually in April and October. Applications for the Friday 17 April 2015 examination must be received by $\mathbf{3}$ January 2015 and for the Friday 16 October 2015 examination by $\mathbf{1}$ July 2015. The syllabus for the Part 1 is on the Faculty website.

\section{Evidence Based Commentary (EBC)}

Candidates can view the released topic and candidate guidance notes for EBC on the Faculty website. There is an absolute deadline of $\mathbf{3 1}$ August $\mathbf{2 0 1 5}$ to submit the EBC on this topic.

\section{Part 2 Examination}

Applications for the MFSRH Part 2 to be held in Liverpool in June $\mathbf{2 0 1 5}$ must be received by $\mathbf{3}$ January 2015.

Further information and the Part 2 Syllabus are on the Faculty website. The qualification is subject to re-certification every 5 years. For the current MFSRH Examination Regulations, information on all components of the MFSRH examination and application forms, please visit the Faculty of Sexual and Reproductive Healthcare website: www.fsrh.org (Examinations) or e-mail Thelma Willock: Thelma@fsrh.org. 